\title{
Data Analysis of Shared Express Box
}

\author{
Qingjuan Ren ${ }^{1, a}$, Yilan Zhang ${ }^{1}$, Shuai Huang ${ }^{1}$, Jiancai Meng ${ }^{1}$ and Xueyi Mo ${ }^{1}$ \\ ${ }^{1}$ Beijing Institude of Graphic communication, Beijing, China \\ a2829480855@qq.com
}

\begin{abstract}
The current use of a large number of packaging materials puts tremendous pressure on the ecological environment and is not conducive to the strategic goal of sustainable development. By using the shared express box, the waste in the process of logistics packaging can be reduced, the resources can be reused and recycled, the consumption of natural resources can be reduced, the reuse rate of packaging can be improved, and the environmental ecological health development can be facilitated. This paper collects the information of the flow of personnel in the fixed area, applies the big data processing method, and analyzes the quantity of different time periods. On this basis, it further analyzes the demand level of the package for the people, and then solves the phenomenon of wasting resources in the modern logistics industry.
\end{abstract}

Keywords: shared express box, application of sharing concept, big data, sustainable development

\section{INTRODUCTION}

Faced with the rapid development of China's express delivery industry, the number of express parcels is also increasing. Since May 2017, the daily express delivery business of national express service companies has exceeded 100 million pieces, marking that China has been regularized into a single-day express delivery. era". Beijing Jiaotong University, Ali Research Institute and Rookie Network jointly released the "National Social E-commerce Logistics Practitioners Research Report". By 2020, the number of e-commerce logistics packages in China is expected to reach 100 billion, and the daily processing capacity is more than 300 million.

\section{THE SOCIAL BACKGROUND OF THE DEVELOPMENT OF "SHARED EXPRESS BOX"}

A low-cost, environmentally-friendly and reusable courier box - the design and use of the shared courier box has entered the line of green logistics. The shared courier box is actually the first recyclable courier box that Suning Logistics has launched. It is a recyclable Packing box. After the consignee receives the courier, the courier will recycle the boxes, each of which can be recycled more than a thousand times. This kind of packaging box can save about one 10-year-old trees per cycle more than 2000 times.

\section{THE "COMMUNICATION BOX" FACING THE BUSINESS LOGIC AND PROMOTION BARRIERS}

\subsection{Cost Issues}

According to the official introduction, the cost of a single courier box is 25 yuan. If the cost is 200,000 , the total cost is 5 million, and the cost of producing a single carton is only a few dollars or even a few cents, compared to the cost of sharing the courier box. Too high, the final cost will be passed on to consumers.

\subsection{The Use of Questions}

From the current point of view, the e-commerce platform does not specify how the shared courier box is applied. Buyers place orders on the e-commerce platform, and there is no option to use the shared courier box on the order page. Because the price of the courier box is higher, consumers are worried about not enjoying the problem of shipping, and the company needs to do further description.

\subsection{Recycling Issues}

The recycling of express carton has always been a difficult problem for the logistics industry. According to the data of the State Post Bureau, over $70 \%$ of users will treat the express package as "junk", and a small number of users will use the express carton for secondary use or other purposes. The shared express box is said to be able to be used more than 1000 times, but it is not easy to implement. For example, when the delivery is not at home, the shared express box cannot be recycled; if the collection point is set in the community, the operating cost will also increase. In the event of a property problem, and the recycling of the courier box is also easy for the courier to create resistance.

\subsection{Privacy Issues}

The shared courier box needs to take out the goods inside before it can be used twice. The consumer is not willing to take out the goods in the face of the courier, which involves user privacy issues.

In summary, the emergence of shared express boxes does reflect the problems of express packaging. In the eyes of the industry, the "shared express box" is actually a courier box that is recycled. Its low cost and environmental protection provide a new way of thinking about solving problems such as over-packaging and express garbage. The "shared courier 
box" looks good, but there are two main factors to consider: cost, penetration.

\section{THE APPLICATION OF GREEN LOGISTICS PACKAGING IN TODAY'S LOGISTICS}

In the current logistics express, each user receives a courier box when purchasing their own goods. After the traditional express delivery and processing improvement, the courier box has multiple users, that is, multiple users can use at different times. This express parcel, a mode of "sharing" a courier package by multiple users, reduces the production of discarded boxes during recycling.

China's State Post Bureau, China Federation of Logistics and Purchasing and other 10 departments jointly issued the "Guiding Opinions on Collaborative Promotion of Green Packaging in the Express Delivery Industry" jointly issued by "Double 11", showing that by 2020, China's biodegradable green packaging materials will be applied. The proportion will rise to $50 \%$, and the average cost per express package will be reduced by more than $10 \%$. Packaging production enterprises, e-commerce enterprises and express delivery enterprises should take the initiative to connect with recycling enterprises, establish a mechanism of combining "Internet plus" platform and offline logistics, and equip the community business outlets with clear-marked express packaging and recycling containers. By 2020, we will promote the use of some shared packaging containers such as transfer boxes and cages. Reduce the use of plastics and basically complete the logistics packaging recycling system.

Finally, the current major logistics companies basically use electronic single sheets instead of the traditional ones, and replace the traditional logistics bags with environmentally-friendly courier bags. New energy electric vehicles and some unmanned storage equipment should be used.

\section{THE EXPRESS BOX SURVEY AT THE FIXED POINT}

The customer flow box is used to help merchants collect enough passenger flow data to provide a solution to monitor merchant traffic and help retail companies better achieve market research. By preserving equipment and data, accurate users can be identified. The passenger flow box has a ground coverage of 30 meters. It can monitor the customer's mobile phone according to the customer's mobile phone, and refresh the data within a certain period of time to monitor the customer's retention time, because each person's mobile
By learning big data processing and analyzing the number of fixed-point express delivery and the demand for the package, and professionalizing the effective data, providing data support for the design of the shared express box, how to record the data becomes a problem we need to think about. Under the condition that the statistical data is accurate, subject to the research conditions, you want to record the number of people who receive the courier every day, monitor the number of people in the camera or calculate the number of people by installing the counter. In the moment, you want to find accurate data, obviously not applicable. . Such a method, there is a large amount of data missing, the detection can not achieve effective accuracy, whether the camera or the counter may face the accuracy of image recognition is not high, and when there are a large number of people, the phenomenon of repeated counting due to confusion, invisibly increased The error of data statistics.

Passenger flow box [1] The author is unknown. Interview with wisdom space Pang Tao: The era of big data, the pioneer of the traditional industry. Competition (2015) (06) is the independent research and development of Beijing Smart Space Technology Co., Ltd. Offline hardware collection products for data collection, Smart Space has a number of independent core technologies such as infinite scanning, wireless tracking and indoor positioning. It has been used in many industries, including retail, education, utilities, and more. The passenger flow box uses wireless WIFI technology to identify wireless devices such as customer mobile phones, so as to accurately obtain valuable data such as passenger flow, storage rate, dwell time and return rate. Through the big data analysis system, generate easy-to-understand passenger flow data reports, help online merchants accurately target the target customer base, and ultimately achieve precise marketing. For big data collection, some Internet companies rely on a large number of online user interactions as data support to achieve precise marketing, efficiency and profitability.

\section{THE USE OF RELEVANT TECHNOLOGY PROCESSING}

phone will emit radio waves. The passenger flow box not only can hear radio waves but also recognizes radio waves, and accurately recognizes the model of the mobile phone device based on the fixed feature code carried by the radio waves during radio wave transmission. Thereby locking the mobile phone user, through this monitoring, the formation of data trend analysis map, repeat customer rankings, etc..We can well understand the fixed-point delivery status. 


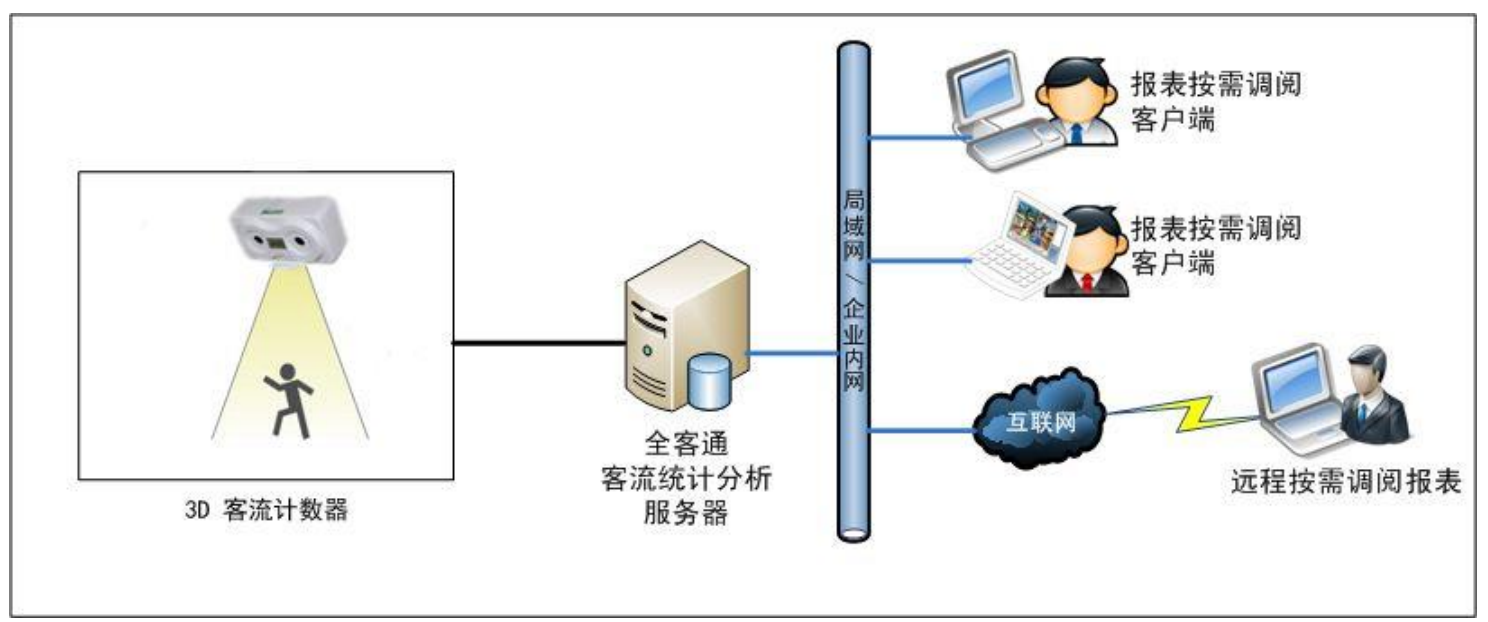

Figure 1 Schematic diagram of the passenger flow box principle

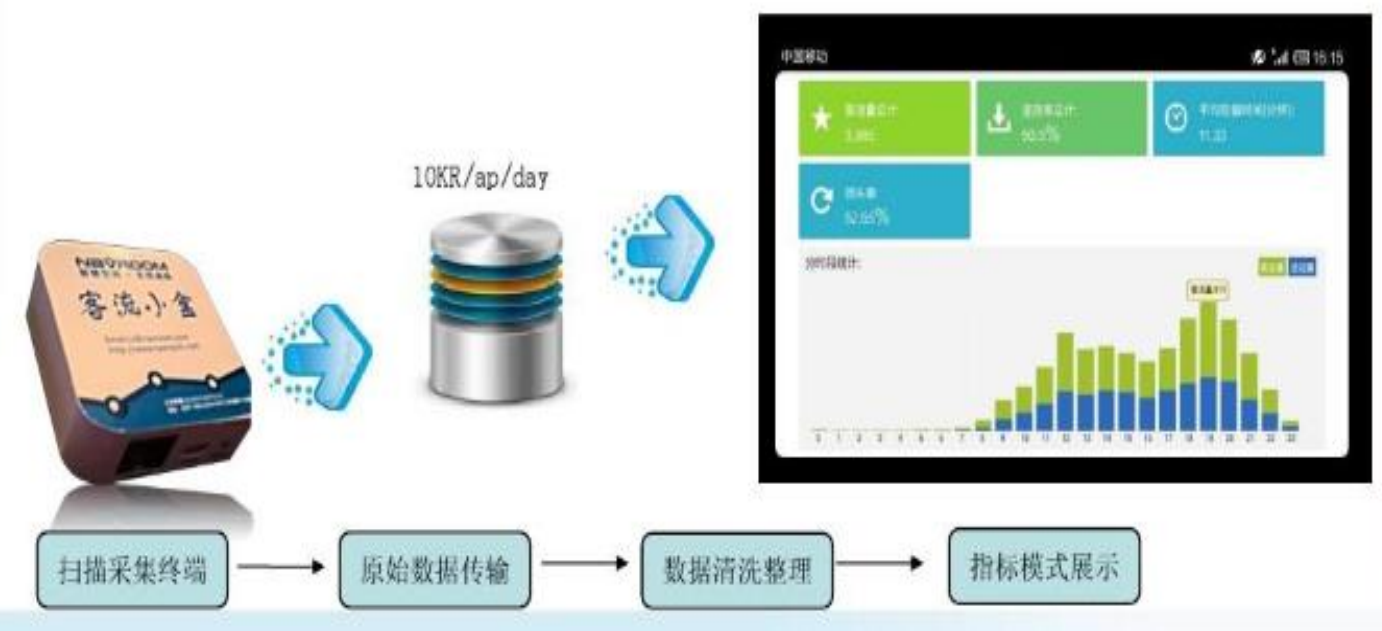

Figure 2 Statistical method for logistics boxes

\section{CONCLUSION}

The concept and initiative of "sharing express box" is beneficial to the country and the people, and is conducive to sustainable development strategy, which is conducive to the improvement and innovation of the logistics industry, but still needs the cooperation of consumers. Undoubtedly, the design and use of the shared courier box provides a new idea for solving the problems of over-packaging and express garbage. If we can design a shared courier box, reduce waste in the process of logistics packaging, enable resources to be reused and recycled, reduce human consumption of natural resources, reduce the cost of input, and improve the reuse rate of packaging. Healthy development has a positive effect.

\section{ACKNOWLEDGMENT}

Special thanks are given to Mr.Yongbin Zhang for his technical help and writing assistance.We greatly appreciate and thank our former group members Qingjuan Ren,Xueyi Mo, Yilan Zhang,Shuai Huang,Jiancai Meng for their careful review and helpful editing of this manuscript. This work was supported in part by National College Student Innovation and Entrepreneurship Project (Project No. 22150119004/028).

\section{REFERENCES}

[1] The author is unknown. Interview with wisdom space Pang Tao: The era of big data, the pioneer of traditional industries. Competition (2015). 